\title{
Editorial
}

\section{ANATOMY IN THE XXI CENTURY: SCIENCE AND HUMANITARIAN ISSUES OF A DISCIPLINE IN CONTINUOUS EVOLUTION}

\section{Chiarella Sforza}

\author{
Department of Biomedical Sciences for Health, Università degli Studi di Milano, Milan, Italy
}

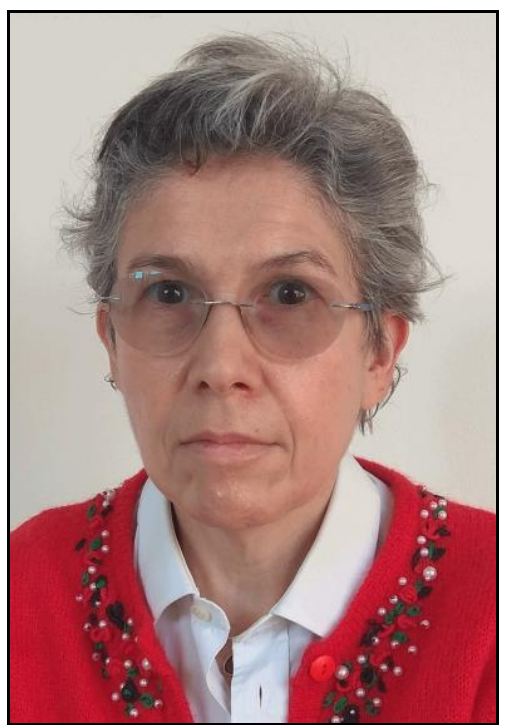

According to Encyclopedia Britannica, Anatomy is "a field in the biological sciences concerned with the identification and description of the body structures of living things" (Encyclopedia Britannica, 2018). When fresh persons enter the medical school, they meet not only a (relatively) new discipline but also "Nomina Anatomica", a new dictionary, a new set of words describing the relationships among the various parts of the body. Additionally, they learn a method of analysis, where observation, either without or with magnifying instruments and imaging tools, division into parts, and description, often supported by measurements, are the key elements. All this will make the base for their course study and future clinical practice.

As everything in science, Anatomy is a dynamic discipline that continues to change and modify to better fulfill its teaching objectives and serve medicine and health sciences in a broader context. The long-established dissection-based practice has incorporated molecular biology, genetics, biological anthropology, biomechanics, imaging, clinical anatomy, etc., all contributing to the analysis and understanding of body structure and organization in the different levels of complexity.

At the same time, other disciplines are changing their characteristics and modifying their research fields and practical applications such as forensic anthropology (Cattaneo, 2007). While classical forensic contributions to delineate a biological profile, with determination of age, sex, ancestry, stature, pathologies, and so on, still remain fundamental, forensic anthropologists are expanding their expertise from body hard tissues to soft tissues, from deceased persons to living individuals (de Boer et al., 2020).

Well inside these evolutions, anatomical observations and methods are also being applied to forensic contexts, to both living and dead persons, thus expanding the above mentioned definition (EB, 2018). Personal identification is one of the emerging scenarios where the two disciplines can fruitfully work and collaborate: actually the assessment of the similarity of two faces is not conceptually different from the assessment of bone similarities. Anatomy can support forensic anthropology in this novel definition of biological profiles.

Classically, bones and teeth are major sources of information, but, depending from the context, also soft tissues can usefully provide data for people identification, from both direct observation and imaging techniques. This may occur for both living and dead persons, for single individuals or for large numbers, as it may happen in mass disasters. 
The identification of the dead has several interconnected facets, involving human rights, family rights, administrative duties, legal aspects, that all stem from the right of human beings to maintain their identity after death. This will allow to inform families about the destiny of their relatives, define the appropriate administrative procedures and eventually prompt the necessary legal actions (de Boer et al., 2020; Olivieri et al., 2018).

It is currently recognized that, alongside with primary identification sources (fingerprints, DNA, dental comparisons, medical/surgical implants with unique serial numbers), personal identification can be supported also by comparison of ante-mortem (AM) and postmortem (PM) records of secondary identifiers, where forensic anthropology plays a key role (de Boer et al., 2020). Even if the secondary identifiers are usually not sufficient for identification, they can contribute in selected occasions, and their use is becoming more and more widespread when other methods are not applicable (Caplova et al., 2018; Olivieri et al., 2018).

At this time, one of the most impressive scenarios of unidentified deceased persons is death during migration, and in particular for Italy the Mediterranean Sea route, from Africa and Middle East towards Europe. According to the Missing Migrants Project developed by the International Organization for Migration (IOM, 2021), during 2020 a minimum of 565 migrants died while travelling in the Mediterranean area towards an international destination. If we add the number of missing people, in the same year, 1421 migrants at least still need to be identified and called by their name (IOM, 2021) ${ }^{1}$. Italy is trying to handle this challenge of personal identification with the joint work of the government, the Italian national police and universities. The first task is the definition of specific $\mathrm{AM}$ and PM data collection protocols (Olivieri et al., 2018).

PM data collection in forensic anthropology and the relevant data analysis techniques can be well supported by existing knowledge in the anatomical sciences, where several research protocols could be applied to this new and emerging field, in particular with the use of imaging techniques, either volumetric or surface-

\footnotetext{
${ }^{1}$ In 2020, the 565 Mediterranean victims represent about $27 \%$ of the worldwide estimate of 2091 persons, and the 1421 missing migrants are about $39 \%$ of the worldwide estimate of 3654 . Both numbers are likely to be underestimated (IOM, 2021).
}

assessing and measuring the three-dimensional characteristics of both soft and hard tissues for the last 30 years, thus providing measurement methods that are free from those projection problems typical of two-dimensional records (Sforza et al., 2013). Indeed, the comparison of $\mathrm{AM}$ and PM morphological features can support personal identification also giving quantitative estimates of the match between the relevant twodimensional or three-dimensional digital models.

For instance, if PM data collection of craniofacial features is performed using three-dimensional scanners like stereophotogrammetry or laser scanning, the resulting digital model can be rotated and translated over the AM record, independently from the orientation of the AM image. The distance between the two superimposed images can measure the discrepancy between the faces, thus helping in separating matches from mismatches (Cattaneo et al., 2012). As a practical example, identification of eight of the deceased in the Lampedusa shipwreck of October 3rd 2013, out of 31 total identifications, was done by using facial, anthropological and odontological methods (Olivieri et al., 2018).

Also, anatomical investigations set the bases for reference data banks that offer the quantitative description of "normalcy", being both the picture of a healthy state and the most frequent situation in the analyzed population. In this context, anatomical variants gain a huge importance, as they can offer alternative identifiers for personal identification. On going investigations are being performed in anatomy laboratories with the precious support of clinical imaging (Gibelli et al., 2018). Additionally, as the description of anatomical "normalcy" is strictly related to the specific population identified by sex, age, ancestry, international collaborations are necessary to fill in the gaps of the current knowledge (Sforza et al., 2016).

In conclusion, anatomy in the XXI Century is something more than anatomy in the Renaissance, not only for the inclusion of modern technologies but also for its contribution to humanitarian issues. It can combine its competences and expertise with those of forensic anthropologists in tasks related to personal identification, possibly helping in the recognition of the victims of migration. The application of well established anatomical protocols will support scientists in this task, calling the dead people by their own names. The classical anatomical mission of providing the dictionary for medicine and allied professions is evolved: alongside with Nomina Anatomica there are the individual names. 


\section{REFERENCES}

The Editors of Encyclopaedia Britannica. 2018. "Anatomy". Encyclopedia Britannica, https://www.britannica.com/science/anatomy (accessed February 2021).

Caplova Z, Obertova Z, Gibelli DM, De Angelis D, Mazzarelli D, Sforza C, Cattaneo C. 2018. Personal identification of deceased persons: an overview of the current methods based on physical appearance. J Forensic Sci 63: 66271.

Cattaneo C. 2007. Forensic anthropology: developments of a classical discipline in the new millennium. Forensic Sci Int 165: 185-93.

Cattaneo C, Cantatore A, Ciaffi R, Gibelli D, Cigada A, De Angelis D, Sala R. 2012. Personal identification by the comparison of facial profiles: testing the reliability of a highresolution 3D-2D comparison model. J Forensic Sci 57: 182-7.

de Boer HH, Obertová Z, Cunha E, Adalian P, Baccino $E$, Fracasso $T$, Kranioti $E$, Lefévre $P$, Lynnerup N, Petaros A, Ross A, Steyn M, Cattaneo C. 2020. Strengthening the role of forensic anthropology in personal identification: Position statement by the Board of the Forensic
Anthropology Society of Europe (FASE). Forensic Sci Int 315: 110456.

Gibelli $D$, Cellina M, Gibelli S, Cappella A, Oliva AG, Termine G, Sforza C. 2018. Anatomical variants of ethmoid bone on multidetector $C T$. Surg Radiol Anat 40: 1301-11.

International Organization for Migration (IOM). 2021. Missing migrants project. https://missingmigrants.iom.int/ (accessed February 2021).

Olivieri L, Mazzarelli $D$, Bertoglio B, De Angelis $D$, Previderè $C$, Grignani $P$, Cappella $A$, Presciuttini S, Bertuglia C, Di Simone P, Polizzi N, ladicicco A, Piscitelli V, Cattaneo C. 2018. Challenges in the identification of dead migrants in the Mediterranean: The case study of the Lampedusa shipwreck of October 3rd 2013. Forensic Sci Int285: 121-28.

Sforza C, de Menezes M, Ferrario V. 2013. Softand hard-tissue facial anthropometry in three dimensions: what's new. J Anthropol Sci 91: 159-84.

Sforza C, Dolci C, Gibelli DM, Codari M, Pucciarelli V, Ferrario VF, Elamin F. 2016. Agerelated and sex-related changes in the normal soft tissue profile of native Northern Sudanese subjects: a cross-sectional study. $\mathrm{Br} \mathrm{J}$ Oral Maxillofac Surg 54: 192-97. 